\title{
О 21-ЛЕТНИХ КОЛЕБАНИЯХ ТЕМПЕРАТУРЫ ВОЗДУХА
}

\author{
В.А.Молодых \\ Главная геофизическая обсерватория им. А.И.Воейкова \\ 194021 Санкт-Петербург, ул. Карбышева, дом 7 \\ E-mail: vam3@ rambler.ru
}

Настоящая работа посвящена вопросу поиска в атмосфере планеты долгопериодных колебаний атмосферных характеристик, в частности, температуры приземного воздуха. В данном случае речь пойдет о колебаниях температуры воздуха с длительностью порядка 20 лет.

Указанная длительность интересна тем, что во внешних факторах, воздействующих на атмосферу Земли, присутствуют цикличность длительностью около 22 лет, обусловленная 22-летним магнитным циклом Солнца, и периодичность 18,6 года, обусловленная приливными эффектами спутника Земли - Луны.

На наличие колебаний температуры воздуха с сопоставимой длительностью указывалось в многочисленных работах. Обзоры таких исследований можно найти в (Логинов, 2020, Шерстюков, 2011).

Результатами этих исследований явились выводы о том, что колебания температуры $\mathrm{c}$ указанными периодами являются неустойчивыми как по длительности, так и сильно локализованы по территории, могут проявляться в одних районах и отсутствовать в других. То же самое касается и сезонов (месяцев) года, когда в разные месяцы наблюдаются разные закономерности. При этом проводимый анализ зачастую ограничивался изучением чисто статистической структуры (спектров) рядов на большом числе станций, без выделения колебаний температуры воздуха в явном виде. 
Поэтому крайне важным является нахождение на поверхности Земли районов, где какая-либо закономерность проявляется устойчиво на протяжении длинного ряда лет.

Автором ранее предпринимались усилия найти колебания температуры воздуха с подобными периодами для территории Северной Америки (Молодых, 1986). Были сделаны следующие выводы:

- при ограниченной длительности рядов наблюдений невозможно четко определить, какова более точная длительность колебаний температуры воздуха, и, тем самым, попытаться выяснить их первопричину. Констатировалось просто наличие квазидвадцатилетних колебаний температуры воздуха,

- цикл длительностью от 18 до 22 лет в рядах месячных температур воздуха в Северной Америке статистически значимо присутствует. При этом повторяемость проявления 22-летнего солнечного цикла несколько превышает повторяемость проявления лунного 18,6-летнего,

- повторяемость квазидвадцатилетнего цикла в изменениях температуры воздуха наиболее высока в зимние месяцы, особенно в январе.

Представлялось интересным провести похожее исследование изменений температуры воздуха с возможным квазидвадцатилетним периодом для другой территории.

\section{1. Исходные данные}

В качестве такой территории была выбрана территория Японии, для которой на сайте Японского метеорологического агентства доступны сведения о средней месячной температуре воздуха ряда станций за период последних 130-145 лет. При этом данные являются наблюдательными, а не расчетными, привязаны к пункту наблюдений, а не к узлу или площади координатной сетки, в высокой степени однородны, практически не имеют пропусков наблюдений и переносов станций. 
Территория Японии была выбрана и по тем соображениям, что климат Японии в силу ее географического расположения является океаническим. Японию омывают два океанских течения, теплое Куросио (с его более мелкими ответвлениями, омывающими западное побережье) и холодное Курильское. Учитывая все возрастающие попытки исследователей найти причины изменений климата в том числе и в изменениях теплосодержания океана, выбор территории для исследования представляется закономерным

С учетом результатов, полученных в предыдущих работах автора, для анализа использовались январские месячные значения температуры воздуха по выбранным 15 станциям Японии, по возможности равномерно распределенным по территории и близким к побережьям для учета возможного влияния океана на атмосферные процессы. Выбирались станции с максимально длинными рядами наблюдений и минимальным количеством пропусков наблюдений.

Сведения о выбранных станциях приведены в табл.1.

Таблица 1. Перечень станций для анализа температуры воздуха

\begin{tabular}{|c|l|c|c|c|}
\hline $\begin{array}{l}\text { № } \\
\text { п.п. }\end{array}$ & $\begin{array}{l}\text { Название } \\
\text { Станции }\end{array}$ & $\begin{array}{c}\text { Широта, } \\
\text { град } \\
\text { с.ш. }\end{array}$ & $\begin{array}{c}\text { Долгота, } \\
\text { град в.д. }\end{array}$ & $\begin{array}{c}\text { Анализируемый } \\
\text { период и длительность } \\
\text { ряда, лет }\end{array}$ \\
\hline 1 & Акита & 39,72 & 140,10 & $1883-2020(138)$ \\
\hline 2 & Исиномаки & 38,43 & 141,3 & $1888-2020(133)$ \\
\hline 3 & Кагосима & 31,55 & 130,55 & $1883-2020(138)$ \\
\hline 4 & Канадзава & 36,59 & 136,63 & $1882-2020(139)$ \\
\hline 5 & Коти & 33,57 & 133,55 & $1886-2020(135)$ \\
\hline 6 & Нагасаки & 32,73 & 129,87 & $1879-2020(142)$ \\
\hline 7 & Наха & 26,21 & 127,69 & $1891-2020(130)$ \\
\hline 8 & Немуро & 43,33 & 145,59 & $1880-2020(141)$ \\
\hline 9 & Ниигата & 37,89 & 139,02 & $1882-2020(139)$ \\
\hline 10 & Сакаи & 35,54 & 133,23 & $1883-2020(138)$ \\
\hline 11 & Саппоро & 43,06 & 141,33 & $1877-2020(144)$ \\
\hline 12 & Суццу & 42,80 & 140,22 & $1885-2020(136)$ \\
\hline
\end{tabular}




\begin{tabular}{|l|l|l|l|l|}
\hline 13 & Токио & 35,69 & 139,75 & $1876-2020(145)$ \\
\hline 14 & Фукуока & 33,58 & 130,38 & $1890-2020(131)$ \\
\hline 15 & Хамамацу & 34,71 & 137,72 & $1883-2020(138)$ \\
\hline
\end{tabular}

\section{2. Методика анализа данных}

В качестве основного метода преобразования исходных данных для их углубленного анализа использовалась цифровая фильтрация. Этот метод представляет собой скользящее осреднение соседних данных с заранее рассчитанными весовыми коэффициентами. Данный метод широко известен в теории обработки сигналов, но в метеорологии общепринято усреднять данные с равными весовыми коэффициентами, используя три, пять, десять и т.п. отсчетов ряда. При таком усреднении в отфильтрованный ряд вносятся искажения, которые создают в ряду колебания, которых исходно там нет.

Примененная здесь методика цифровой фильтрации для анализа климатических рядов в работах других авторов не использовалась.

Каждый ряд январских температур по 15 станциям подвергался двум преобразованиям.

1. Удалялась долгопериодная составляющая путем расчета и вычитания из исходного ряда параболического тренда. Очевидно, что такое преобразование направлено на исключение векового хода температуры.

2. Полученный ряд температур подвергался скользящей фильтрации с применением нерекурсивного цифрового фильтра низких частот по методу наименьших квадратов с окном Ханна (Хемминг, 1980). Число весовых коэффициентов фильтра было выбрано равным 41. Частота обрезания фильтра задавалась равной 0,075 , что соответствует периоду 13,3 года.

Полученные в результате преобразований по пп.1-2 данного раздела подвергались автокорреляционному анализу, как простому и понятному, без внесения в методику дополнительных предположений, свойственных современным методам анализа спектров (Пановский и 
др., 1967). Максимальная величина запаздывания выбиралась равной 40 отсчетам ряда.

Остановимся коротко на свойствах использовавшегося цифрового фильтра.

Передаточная функция фильтра, характеризующая его особенности, представлена на рис.1.

Применение указанного метода фильтрации позволяет сглаживать (вырезать) в исходном ряду короткопериодные колебания (высокие частоты, межгодовая изменчивость), оставляя только долгопериодные колебания (низкие частоты).

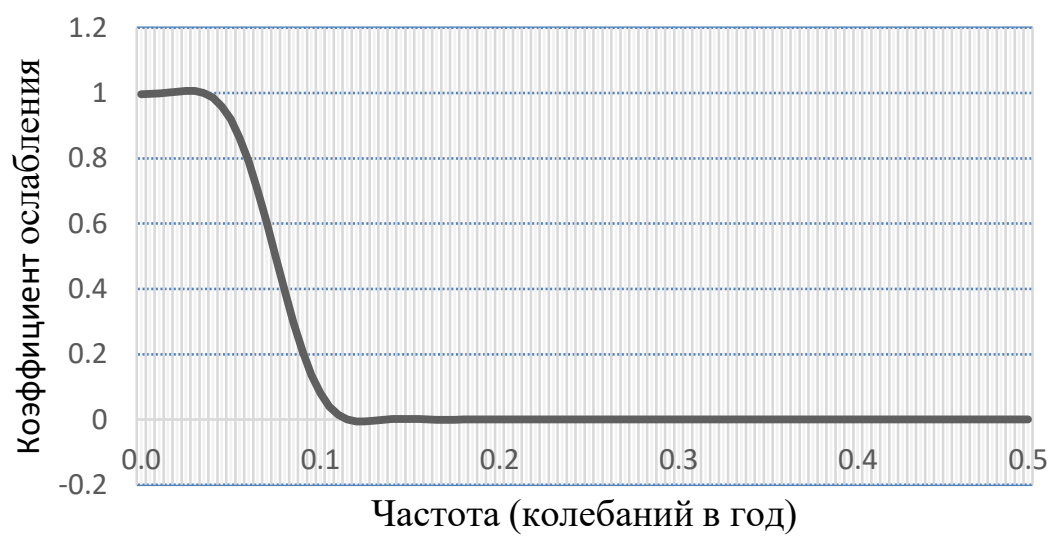

Рис.1. Передаточная функция фильтра

В табл.2 приведены характерные точки и значения передаточной функции (коэффициента ослабления) фильтра в зависимости от частоты (периода) колебаний в анализируемом ряду.

Из таблицы видно, что примененный метод фильтрации практически не меняет амплитуды низкочастотных колебаний. При частотах колебаний, сопоставимых с 20-летними, амплитуды колебаний могут уменьшаться на 8-14 \% (строки 3-4 таблицы).

Амплитуды возможных колебаний с периодами около 10-11

Таблица 2. Характеристики цифрового фильтра 


\begin{tabular}{|c|c|c|c|}
\hline $\begin{array}{r}\text { № } \\
\text { п.п. }\end{array}$ & $\begin{array}{c}\text { Частота } \\
\text { колебания, } \\
(1 / \text { год) }\end{array}$ & $\begin{array}{c}\text { Период } \\
\text { колебания } \\
(\text { лет) }\end{array}$ & $\begin{array}{c}\text { Значение } \\
\text { передаточной } \\
\text { функции }\end{array}$ \\
\hline 1. & $<0.04$ & $>25$ & $\approx 1.00$ \\
\hline 2. & 0.04 & 25 & 0.986 \\
\hline 3. & 0.05 & 20 & 0.919 \\
\hline 4. & 0.055 & 18.2 & 0.863 \\
\hline 5. & 0.06 & 16.6 & 0.790 \\
\hline 6. & 0.07 & 14.3 & 0.604 \\
\hline 7. & 0.075 & 13.3 & 0.500 \\
\hline 8. & 0.08 & 12.5 & 0.396 \\
\hline 9. & 0.09 & 11.1 & 0.21 \\
\hline 10. & 0.10 & 10 & 0.08 \\
\hline 11. & 0.11 & 9.1 & 0.01 \\
\hline 12. & $>0.11$ & $<9.1$ & $\approx 0.00$ \\
\hline
\end{tabular}

лет при фильтрации уменьшаются в 5-10 раз, то есть в значительной мере такие колебания отфильтровываются (строки 9-10 таблицы).

Колебания с периодами 9 и менее лет отфильтровываются полностью, их амплитуды уменьшаются в 100 и более раз (строки 1112).

Поскольку в состав использовавшегося фильтра входит 41 весовой коэффициент, длина ряда в процессе анализа уменьшается на 40 отсчетов (лет). Столь существенная потеря данных при анализе является своеобразной платой за точность анализа долгопериодных колебаний.

Использовавшийся цифровой фильтр является симметричным, поэтому фазовые сдвиги в отфильтрованном ряду отсутствуют. Это позволяет анализировать возможные связи с рядами данных, отражающими внешнее воздействие на атмосферу. 


\section{3. Результаты}

В табл.3 приведены результаты расчетов автокорреляционных функций $\mathrm{R}$ временных рядов январских температур воздуха по 15 станциям различных районов Японии после удаления из них векового тренда и короткопериодных составляющих. Максимальное запаздывание для $\mathrm{R}$ задавалось равным 40.

Таблица содержит названия станций, периоды анализа в годах, длительность рядов в годах, выявляемые экстремумы (периодичности) и соответствующие им значения автокорреляционных функций. Поскольку процедура фильтрации может создавать связность между членами временного ряда, то основное внимание обращалось на общий вид автокорреляционных функций, без оценки статистической значимости коэффициентов.

Таблица 3. Характеристики автокорреляционных функций январских температур по станциям Японии

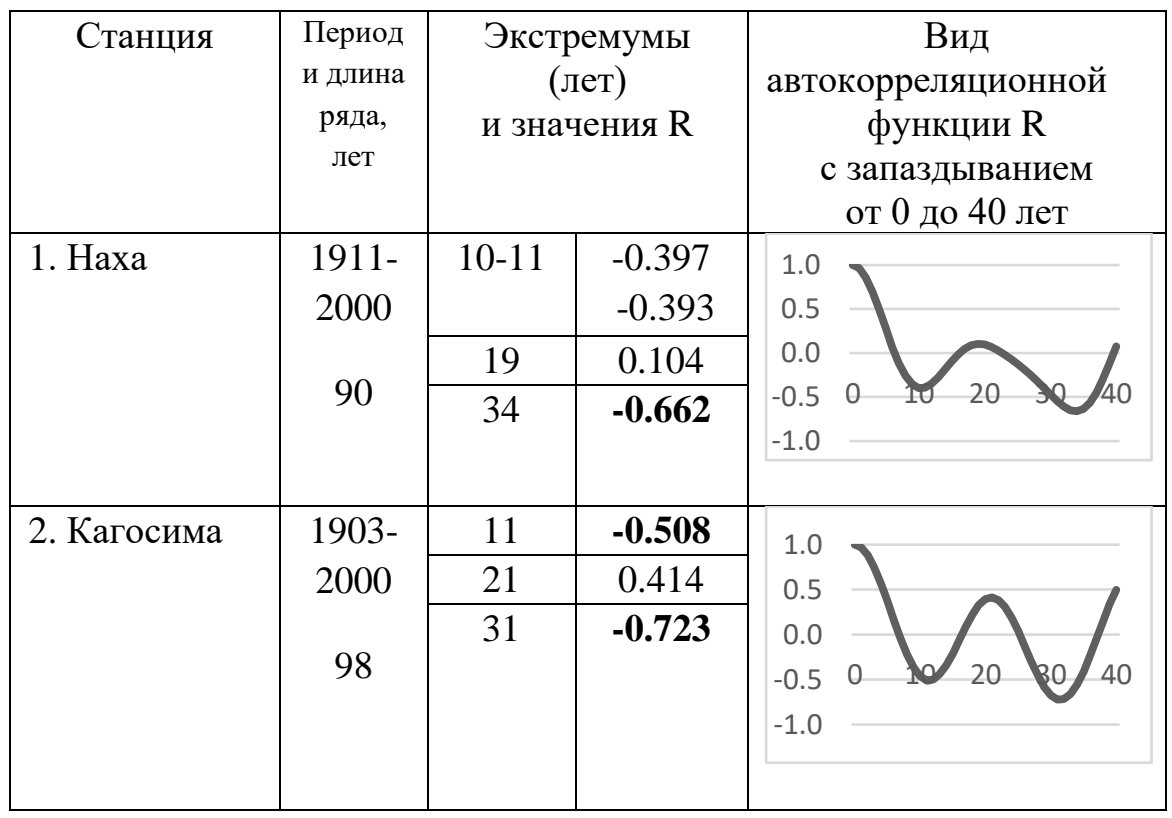




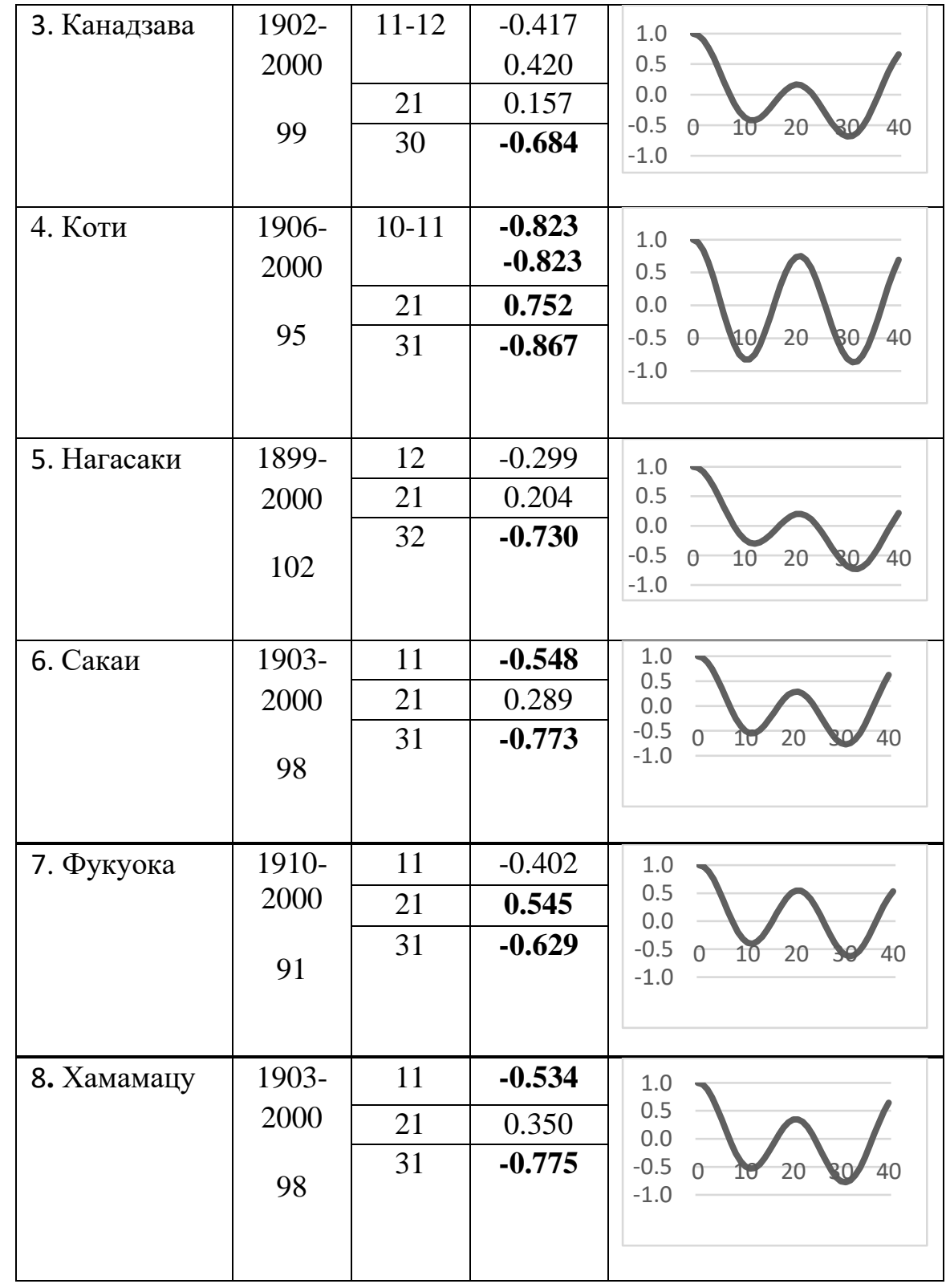




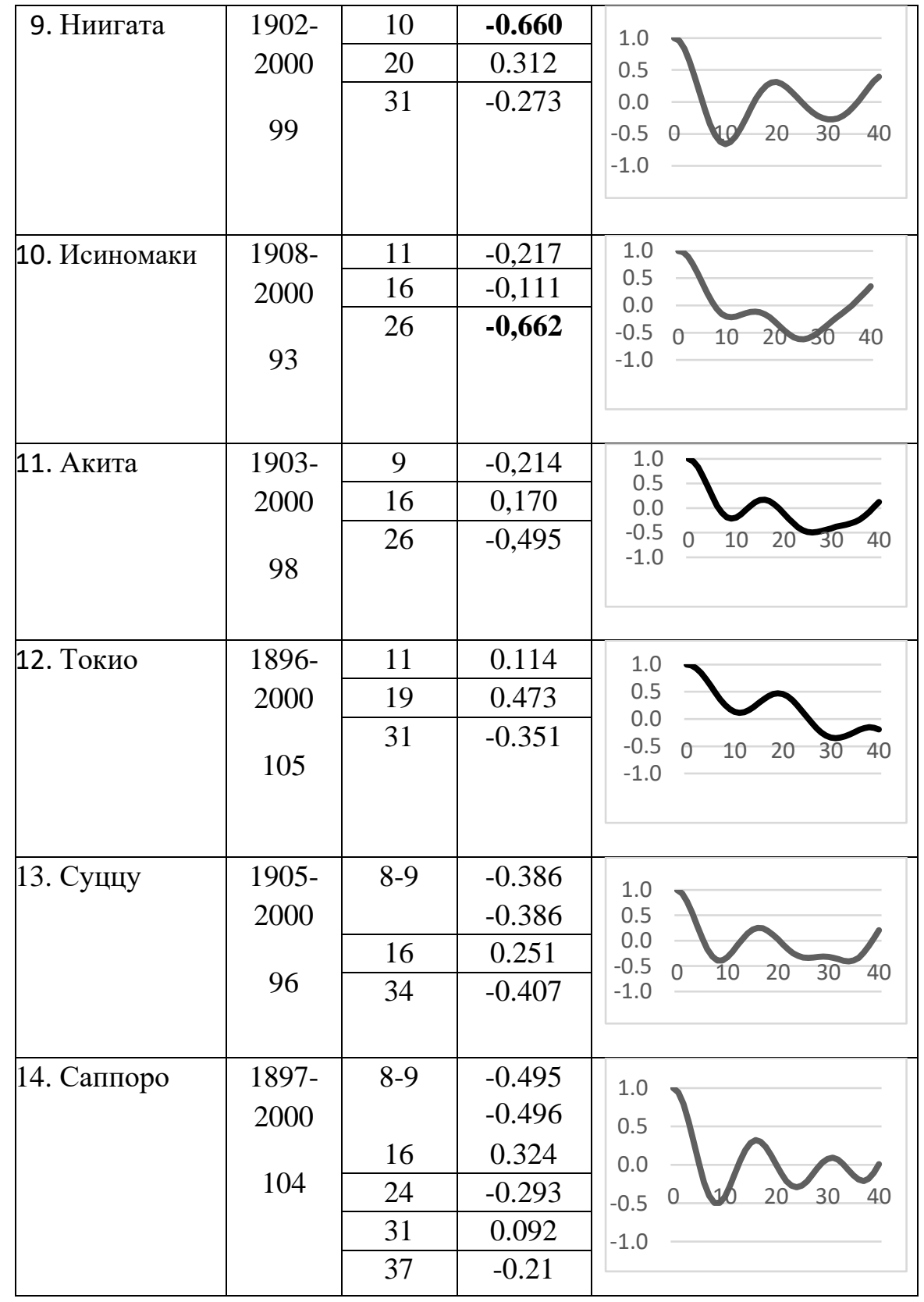




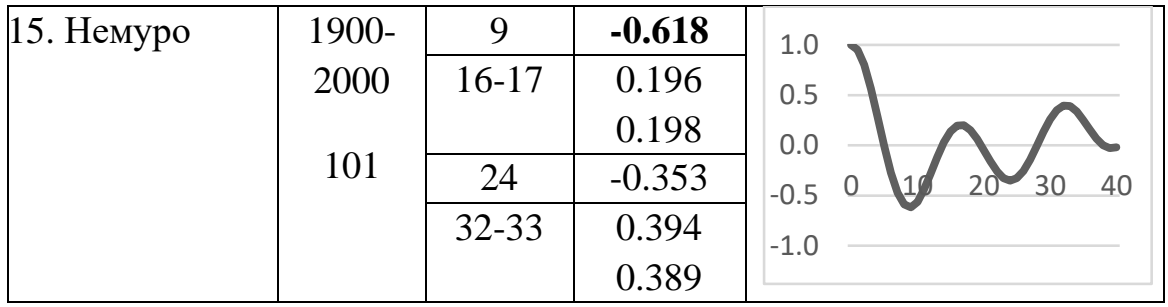

Основное внимание обращалось не только на абсолютные значения R, но и на общий вид графиков. Если на графике выделяются экстремумы (максимумы и минимумы) с периодом, совпадающим или кратным какому-то значению, то это обстоятельство является дополнительным подтверждением присутствия в исходном ряду колебаний с таким периодом, или превышающим его в определенное количество раз.

Значения коэффициентов автокорреляции, превышающие по абсолютной величине 0.5 , в таблице выделены жирным начертанием.

Анализ вида графиков в табл.3, характерных значений периодов экстремумов и их величин позволяет отметить закономерность наличие первого экстремума - минимума значений $\mathrm{R}$ - при задержках 10-11-12 лет.

Величина $\mathrm{R}$ для десяти станций, расположенных на юге и в центральной части Японии, как на западном побережье, так и на восточном, при этих задержках колеблется от -0,2 до -0,8. Наибольшие по модулю значения R отмечаются для станций Кагосима, Канадзава, Коти, Сакаи, Фукуока, Хамамацу, Ниигата. Экстремально большое по модулю значение $\mathrm{R}$ при запаздывании 10-11 лет определяется для ст. Коти $(-0,823)$, следующее за ним - для ст.Ниигата $(-0,660)$, затем для ст.Сакаи $(-0,548)$.

Для более северных станций первый экстремум $\mathrm{R}$ соответствует запаздываниям 8-9 лет и составляет, например, для ст.Немуро -0,618 (9 лет), ст.Саппоро -0,495 (8-9 лет), ст.Суццу -0,386 (8-9 лет).

При рассмотрении второго экстремума рядов $\mathrm{R}$ выделялись периоды, близкие к 16 годам (пять станций), 19 годам (три станции), 20 годам (одна станция), 21 году (семь станций). При этом значения $\mathrm{R}$ для периодов 16 и 19 лет находились в основном на небольшом уровне (0,1- 
0,3). Исключением является станция Токио, для которой для периода 19 лет значение $\mathrm{R}$ равно 0,473.

Для периода 21 год наибольшие значения $\mathrm{R}$ составили на ст. Коти $(0,752)$, Фукуока $(0,545)$, Кагосима $(0,414)$.

Третий экстремум рядов $\mathrm{R}$ попадает в интервал 30-34 года для 11 станций из 15. При этом третий экстремум - отрицательный по знаку. В интервал 30-32 года третий экстремум попадает у 9 станций, и составляет в среднем $-0,643$. Для ст.Коти экстремум равен $-0,867$, ст. Хамамацу: - 0,775, ст. Сакаи: -0.773 , ст.Нагасаки: $-0,730$, ст. Кагосима: $-0,723$, ст. Канадзава: $-0,684$, ст. Фукуока: $-0,629$, ст. Токио: -0.351 , ст. Ниигата: -0,273. Период 30-32 года соответствует по длительности полутора 21-22 летним солнечным циклам.

Обобщая изложенное, можно утверждать, что для нескольких станций Японии в автокорреляционных функциях последовательно выделяются экстремумы с периодами около 11, 21 и 31 года. Причем первый и третий экстремумы отрицательны по знаку, и третий экстремум по модулю зачастую больше первого.

Этими станциями являются Кагосима, Канадзава, Коти, Нагасаки, Сакаи, Фукуока, Хамамацу, Ниигата. Они расположены в южной и центральной части территории Японии.

На севере Японии такой закономерности не выявлено. Там, скорее, выделяются характерные периоды 8-9 и 16 лет.

В качестве иллюстрации вида сглаженных рядов январской температуры воздуха на различных станциях в Японии на рис.1. приведены графики многолетних изменений январских температур воздуха по трем станциям. Там же приведена модифицированная кривая годовых чисел Вольфа. Модификация проводилась путем нормирования чисел Вольфа в 11-летнем цикле на единицу, так что максимумы всех циклов выравнивались по высоте. В нечетных 11летних циклах значения брались со знаком «минус», в четных - со знаком «плюс».

Многолетний ход температуры на рис.1 отчетливо демонстрирует колебания с периодом, близким к 21-22-летнему солнечному. При этом наступление максимумов температур с таким 
периодом наблюдается с запаздыванием на 1-5 лет относительно максимумов 22-летнего цикла чисел Вольфа.

Еще одной особенностью является чередование высот максимумов температуры воздуха в 22-летнем солнечном цикле: высокий - низкий - высокий - низкий - высокий, что косвенно указывает на существование 44-летнего цикла колебаний температуры. Об этом же говорит наличие значительных отрицательных коэффициентов автокорреляции для задержек 30-34 года, соответствующих по длительности трем четвертям 44-летнего солнечного цикла.

Размах температурных колебаний внутри 22-летнего цикла

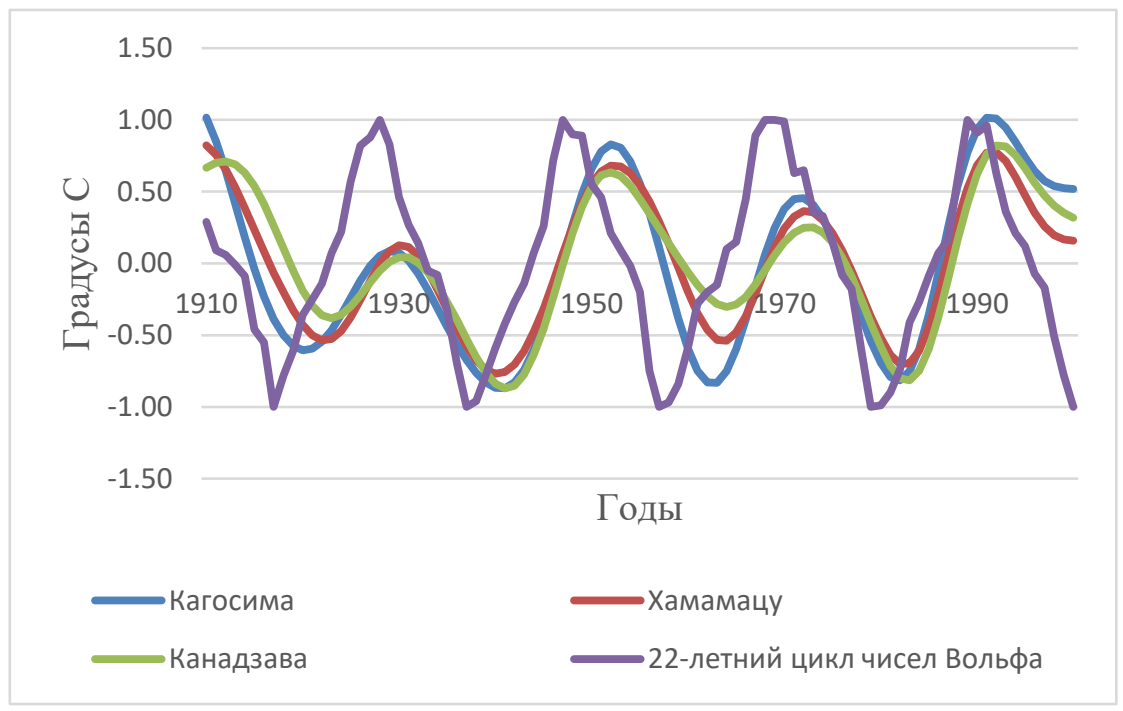

Рис.1. 21-летние колебания январских температур воздуха в Японии.

составляет $1,0-1,5{ }^{\circ} \mathrm{C}$, что является не таким уж большим значением. Однако климат Японии на значительной части территории является океаническим, где изменчивость средней месячной температуры от 
года к году гораздо меньше, чем на континентах в средних и высоких широтах.

Проведенный отдельно анализ автокорреляционной функции модифицированного ряда чисел Вольфа в 20-м столетии показал наличие максимума R при задержке в 21 год, а не в 22 года. Тем самым длительность так называемого солнечного 11-летнего цикла в изучаемый период составила в среднем 10,5 года, а двойного солнечного цикла - 21 год. Этим обстоятельством, при допущении определенного влияния солнечной активности на атмосферные и океанические процессы, хорошо объясняется наличие экстремумов автокорреляционной функции $\mathrm{R}$ рассмотренных температурных рядов для периодов 10-11, 21, 30-32 года.

Учитывая близкую расположенность большинства рассмотренных станций к морю, можно предположить, что механизм, вызывающий обнаруженные в работе квазидвадцатилетние колебания температуры, связан с переменным энергосодержанием океана и океанических течений. В подтверждение этого обстоятельства говорит тот факт, что 21-22 летние колебания температуры наблюдаются на территориях, находящихся под влиянием теплого океанического течения Куросио (юг Японии, запад и восток ее центральной части).

Более северные территории с востока находятся под влиянием холодного Курильского течения. Именно на севере Японии и изменяется частотный состав колебаний, и 21-22-летняя цикличность там не наблюдается.

Анализ температурных рядов за другие месяцы года, кроме января, не позволил выявить найденные для январских температур закономерности. Это говорит об ограниченном воздействии рассмотренных внешних факторов на климатическую систему, и об их сезонном и региональном характере. Аналогичные выводы были сделаны ранее в работе (Шерстюков, 2016).

\section{Заключение}

1. Анализ рядов январских температур воздуха на 15 длиннорядных станциях на территории Японии показал наличие 
устойчивых колебаний с характерной длительностью, соответствующей длительности 21-22-летнего солнечного цикла, для южных и центральных районов рассмотренной территории. Данное обстоятельство позволяет локализовать район на поверхности Земли, где отдельные внешние климатообразующие факторы проявляются наилучшим образом.

2. Размах колебаний температуры в указанном цикле составляет 1,0-1,5 ${ }^{\circ} \mathrm{C}$. Максимумы колебаний температуры в 21-22-летнем цикле наблюдаются спустя 1-5 лет после максимумов двойного солнечного цикла, то есть после максимумов четных 11-летних циклов.

3. Применение использовавшейся в работе низкочастотной цифровой фильтрации данных с узкой переходной областью показало возможность обнаружения и выделения малых по амплитуде климатических колебаний квазидвадцатилетней длительности.

\section{Список литературы}

Логинов В.Ф. Космические факторы климатических изменений. Институт природопользования Национальной академии наук Беларуси, Минск, 2020. - 168 с.

Молодых В.А. Об изменениях среднемесячных температур воздуха в Северной Америке с периодом около 20 лет. Труды ГГО, 1986, вып.503, с.142-148.

Пановский Г.А., Брайер Г.В. Статистические методы в метеорологии. Л., Гидрометеоиздат, 1967. - 242 с.

Сайт Японского метеорологического агентства (https://www.data.jma.go.jp/obd/stats/data/en/smp/index.html).

Хемминг Р.В. Цифровые фильтры. М., Советское радио, 1980. - 224 c.

Шерстюков Б.Г. Изменения, изменчивость и колебания климата. Обнинск, ВНИИГМИ-МЦД, 2011. - 294 с.

Шерстюков Б.Г. Климатические условия Арктики и новые подходы к прогнозу изменения климата. - Арктика и Север, 2016, № 24, с.39-67. 


\section{Аннотация}

Анализ рядов январских температур воздуха на 15 длиннорядных станциях на территории Японии с применением низкочастотной цифровой фильтрации показал наличие устойчивых колебаний с характерной длительностью, соответствующей длительности двойного солнечного цикла (21 год), для южных и центральных районов рассмотренной территории.

Размах колебаний температуры в указанном цикле составляет 1,0-1,5 ${ }^{\circ} \mathrm{C}$. Максимумы колебаний температуры в 21-летнем цикле наблюдаются спустя 1-5 лет после максимумов двойного солнечного цикла, то есть после максимумов четных 11-летних циклов. 